\title{
Effects of exposure to carbon disulphide on low density lipoprotein cholesterol concentration and diastolic blood pressure
}

\author{
Grace M Egeland, Greg A Burkhart, Teresa M Schnorr, Rick W Hornung, John M Fajen, \\ Shiu T Lee
}

\begin{abstract}
The relation of carbon disulphide $\left(\mathrm{CS}_{2}\right)$ exposure to risk factors for ischaemic heart disease was recently examined using data from a 1979 cross sectional study of $\mathbf{4 1 0}$ male textile workers, of whom 165 were exposed and 245 were unexposed to $\mathbf{C S}_{2}$. Average eight hour $\mathbf{C S}_{2}$ exposure concentrations ranged from 0.6 to $11.8 \mathrm{ppm}$ by job title category among the exposed workers. A significant and positive linear trend in low density lipoprotein cholesterol concentration $\left(L D L_{c}\right)$ and diastolic blood pressure with increasing $\mathrm{CS}_{2}$ exposure was found after adjustment for potential confounders. When exposure was examined as a categorical variable (none, low, moderate, and high), the high exposure group had an adjusted mean $L L_{c}$ that was $0.32 \mathrm{mmol} / 1$ greater than the non-exposed group $(p=0.02)$, and an adjusted mean diastolic blood pressure that was $3.16 \mathrm{~mm} \mathrm{Hg}$ greater than the non-exposed group $(p=0.09)$. The effect of $\mathrm{CS}_{2}$ on diastolic blood pressure was strengthened in analyses limited to exposed workers: the high exposure group had an adjusted mean diastolic blood pressure that was $5 \mathrm{~mm} \mathrm{Hg}$ greater than that of the low exposed group $(p=0.03)$. Triglyceride, high density lipoprotein cholesterol, and fasting glucose concentration, and systolic blood pressure were not affected by exposure. Blood lead concentration was positively associated with systolic and diastolic blood pressure. The results indicate that relatively modest exposure to $\mathrm{CS}_{\mathbf{2}}$ may raise $\mathrm{LDL}_{\mathrm{c}}$ concentration
\end{abstract}

National Institute for Occupational Safety and Health, Industrywide Studies Branch, 4676 Columbia Parkway, Cincinnati, OH 45226

G M Egeland, G A Burkhart, T M Schnorr, R W Hornung, J M Fajen, S T Lee and diastolic blood pressure and suggest mechanisms by which exposure to $\mathrm{CS}_{2}$ may influence risk of ischaemic heart disease. Also the results provide further support for the hypothesis of a possible association between blood lead concentration and blood pressure.

Exposure to carbon disulphide $\left(\mathrm{CS}_{2}\right)$ is a well established risk factor for mortality from ischaemic heart disease. ${ }^{1-5}$ Tiller and colleagues, in Great Britain, found that workers with 10 or more years of exposure to $\mathrm{CS}_{2}$ had a greater than twofold excess mortality from ischaemic heart disease than non-exposed workers. ${ }^{4}$ In Finland, a nearly fivefold excess in mortality from ischaemic heart disease was found among viscose rayon workers compared with paper mill workers. ${ }^{2}$ The effect of $\mathrm{CS}_{2}$ exposure on ischaemic heart disease appears to be reversible: the excess mortality from ischaemic heart disease in the Finnish cohort disappeared after the initiation of a prevention programme that removed most workers from exposure and greatly reduced $\mathrm{CS}_{2}$ exposure concentrations for the others. ${ }^{6}$ Similarly, in a follow up study of rayon workers in Great Britain, cumulative exposure among workers whose exposure had ceased for one or more years was not related to increases in mortality from ischaemic heart disease. ${ }^{5}$

Despite the well established association of exposure to $\mathrm{CS}_{2}$ with ischaemic heart disease, few studies have attempted to examine the possible mechanisms that may mediate the effect of $\mathrm{CS}_{2}$ on risk of ischaemic heart disease. ${ }^{1-27-9}$ These studies report no significant differences in electrocardiographic abnormalities, ${ }^{17}$ glucose metabolism, or serum triglyceride concentrations ${ }^{9} ; \mathrm{CS}_{2}$ has been associated, however, with increases in blood pressure, ${ }^{12}$ and with increases in total cholesterol concentration in some ${ }^{810}$ but not all ${ }^{1}$ studies. Although the mechanisms for the putative effect of $\mathrm{CS}_{2}$ on lipids and blood pressure have not been established, $\mathrm{CS}_{2}$ impairs thyroid activity $^{11}$ and alters catecholamine metabolism. ${ }^{12}$ These, in turn, could influence lipid metabolism and vasoregulation. 
We examined the relation of exposure to $\mathrm{CS}_{2}$ to total serum cholesterol, low and high density lipoprotein cholesterol, triglyceride, and fasting glucose conclentrations, and systolic and diastolic blood pressure, using existing data from a cross sectional study conducted in $1979 .{ }^{13}$ Other findings from this study have been described previously. ${ }^{13-15}$ Although the data presented here were collected over 11 years ago, the findings contribute to our current understanding of the association of $\mathrm{CS}_{2}$ with risk of ischaemic heart disease.

\section{Methods}

STUDY POPULATION

In 1979, participants for the cross sectional study were recruited from current employees of a synthetic textile company operating four artificial fibre plants in a small community in Tennessee. ${ }^{13}$ Workers exposed to $\mathrm{CS}_{2}$ were recruited from employees who had worked for a minimum of one year in the viscose rayon plant. The comparison group of non-exposed workers was recruited from employees who had worked for at least one year in the three other plants (polyester filament, nylon filament, and nylon polyester staple plants) and had never worked in the viscose rayon plant or in a previously closed rayon filament plant. Of the 273 exposed men in the viscose rayon plant, $69 \cdot 2 \%$ (189) agreed to participate. Of the 422 workers not exposed to $\mathrm{CS}_{2}, 58 \cdot 1 \%$ (245) agreed to participate. No data are available on the demographic characteristics of the non-participants.

Exposed workers were divided into three exposure groups: low, moderate, and high. The classification was established before the field work and was based on information about the manufacturing process, exposures associated with current job assignment, and company data on historical exposure. ${ }^{13}$ Table 1 lists the job titles used to group workers into the low, moderate, and high exposure categories. Twenty four workers were excluded from the analyses because they could not be categorised into a single exposure group. Of the 165 exposed workers, 48 were categorised into the low, 67 into the moderate, and 50 into the high exposure groups.

To estimate the current $\mathrm{CS}_{2}$ exposure concentration of the three exposure groups at the time of the study, eight hour time weighted average (TWA) personal breathing zone samples were collected from some workers in each job category. Samples were collected with $150 \mathrm{mg}$ charcoal adsorption tubes at a flow rate of $20 \mathrm{ml} / \mathrm{min}$ using calibrated $\mathrm{MDA}$ and duPont low flow sampling pumps. Charcoal samples were desorbed with benzene and analysed by gas chromatography. ${ }^{16}$ The personal samples were collected on 12 days in March and April 1979. Although we use the relative terms, low, moderate,

Table 1 Personal eight hour time weighted average $\mathrm{CS}_{2}$ exposure (ppm) by job assignment and exposure category among rayon workers

\begin{tabular}{|c|c|c|c|c|}
\hline \multirow[b]{2}{*}{ Exposure/job title } & \multirow[b]{2}{*}{ No of samples } & \multirow[b]{2}{*}{$\operatorname{Mean}(S D)$} & \multicolumn{2}{|c|}{ Range } \\
\hline & & & Min & $\operatorname{Max}$ \\
\hline $\begin{array}{l}\text { Low: } \\
\text { Lye room operator } \\
\text { Soaking press loader } \\
\text { Soaking press operator } \\
\text { Shredder operator } \\
\text { Correction operator } \\
\text { Salt unit operator } \\
\text { Sand filter operator } \\
\text { Chemical mix operator } \\
\text { Dryer operator } \\
\text { Bale weigh operator }\end{array}$ & $\begin{array}{l}5 \\
2 \\
2 \\
6 \\
3 \\
3 \\
5 \\
3 \\
1 \\
5\end{array}$ & $\begin{array}{ll}0.6 & (0.40) \\
1.1 & (0.34) \\
1.1 & (0.35) \\
2.5 & (1.62) \\
1.3 & (0.56) \\
0.2 & (0.16) \\
1.7 & (0.70) \\
0.6 & (0.34) \\
1.1 & - \\
0.7 & (0.39)\end{array}$ & $\begin{array}{l}0.04 \\
0.90 \\
1.01 \\
0.99 \\
0.62 \\
0.04 \\
0.95 \\
0.34 \\
0.04\end{array}$ & $\begin{array}{l}0.99 \\
1.38 \\
1.51 \\
5.53 \\
1.60 \\
0.37 \\
2.83 \\
0.97 \\
-1.02\end{array}$ \\
\hline $\begin{array}{l}\text { Moderate: } \\
\text { Dissolver operator } \\
\text { Receiving/filtration } \\
\text { Spinning tank operator } \\
\text { General relief operator } \\
\text { Press packer } \\
\text { Crystalliser/evaporator } \\
\text { Dye mix operator }\end{array}$ & $\begin{array}{r}17 \\
2 \\
2 \\
22 \\
6 \\
4 \\
7\end{array}$ & $\begin{array}{ll}4 \cdot 1 & (1.57) \\
3.7 & (0.24) \\
3.4 & (0.05) \\
4.4 & (2.57) \\
4.7 & (1.42) \\
4.2 & (4.54) \\
5.1 & (1.98)\end{array}$ & $\begin{array}{l}1.89 \\
3.50 \\
3 \cdot 33 \\
0.04 \\
3.31 \\
1.39 \\
3 \cdot 37\end{array}$ & $\begin{array}{r}7 \cdot 90 \\
3 \cdot 84 \\
3.41 \\
11 \cdot 20 \\
6.90 \\
11 \cdot 02 \\
9 \cdot 00\end{array}$ \\
\hline $\begin{array}{l}\text { High: } \\
\text { Churn operator } \\
\text { Tank cleaner } \\
\text { Staple spinner } \\
\text { Tow patroller } \\
\text { Cutter operator } \\
\text { Washer operator }\end{array}$ & $\begin{array}{r}20 \\
2 \\
54 \\
3 \\
13 \\
30\end{array}$ & $\begin{array}{rr}7 \cdot 1 & (3 \cdot 12) \\
8.0 & (10.00) \\
8.8 & (7.41) \\
11.8 & (5.48) \\
11.3 & (7.08) \\
6.1 & (2.92)\end{array}$ & $\begin{array}{l}1.15 \\
0.95 \\
1.28 \\
6.09 \\
0.04 \\
1.01\end{array}$ & $\begin{array}{l}16 \cdot 10 \\
15 \cdot 10 \\
33 \cdot 90^{\star} \\
17 \cdot 00 \\
30 \cdot 70 \\
14 \cdot 40^{\dagger}\end{array}$ \\
\hline
\end{tabular}

$\star$ Excluding one outlier of $216 \cdot 0 \mathrm{ppm}$.

tExcluding one outlier of $159 \cdot 0 \mathrm{ppm}$. 
and high for the three exposure groups throughout the paper, we emphasise that the median $\mathrm{CS}_{2}$ exposure concentrations for all three exposure groups were low: $1.0 \mathrm{ppm}$ for the low, $4.1 \mathrm{ppm}$ for the moderate, and $7.6 \mathrm{ppm}$ for the high exposure groups. ${ }^{15}$ Table 1 lists the mean and range of exposure concentrations associated with each job category in each exposure group. Although the exposure data showed some variability, the personal exposure sampling verified the prior classification of workers into low, moderate, and high exposure categories: the mean TWA exposures for the job titles ranged from 0.6 to $2.5 \mathrm{ppm}$ in the low exposure group, from 3.4 to $5.1 \mathrm{ppm}$ in the moderate exposure group, and from 6.1 to $11.8 \mathrm{ppm}$ in the high exposure group.

As well as $\mathrm{CS}_{2}$ exposure concentrations, other occupational exposures were assessed during the fieldwork. Workers exposed to $\mathrm{CS}_{2}$ were potentially exposed to hydrogen sulphide, whereas workers in the comparison group were potentially exposed to caprolactam, ethylene glycol, dimethyl terephthalate, and methanol. Personal eight hour air sampling was conducted to determine the extent of other chemical exposures. At the time of sampling, exposures to the compounds mentioned were negligible. ${ }^{17}$ All five samples tested for methanol and all 11 samples tested for dimethyl terephthalate were below the limit of detection $(0.9 \mathrm{ppm}$ and $0.015 \mathrm{ppm}$ respectively). Eleven of 12 samples tested for caprolactam were below the limit of detection $(0 \cdot 14$ $\mathrm{ppm}$ ), and the remaining sample (3.9 ppm) was below the $5 \mathrm{ppm}$ standard of the United States Department of Labor, Occupational Safety and Health Administration (OSHA) and the $4.3 \mathrm{ppm}$ recommended standard set by the American Conference of Governmental Industrial Hygienists (ACGIH).$^{18}$ Seventeen samples were analysed for hydrogen sulphide and showed low concentrations ranging from $0 \cdot 1$ to 1.9 ppm; concentrations well below the ACGIH standard of $10 \mathrm{ppm} .{ }^{18}$ The eight samples analysed for ethylene glycol had concentrations ranging from 0.32 to $10.1 \mathrm{ppm}$; these were well below the OSHA standard and the ACGIH recommended standard of $50 \mathrm{ppm} .{ }^{18}$ Although no environmental monitoring was conducted for lead, blood lead concentrations were determined for all study participants because of the potential for exposure to lead during maintenance operations with lead solder.

The risk factors for ischaemic heart disease were measured during the 1979 cross sectional study. Blood pressure was measured after each worker had been in a supine position for a minimum of 10 minutes. All measurements were made by one technician using a random zero sphygmomanometer to minimise observer error. The average of two readings was used in the analyses. Fasting morning venous blood samples were collected on $94 \%$ (385) of the 410 participants to obtain serum for laboratory analyses of total cholesterol, high density lipoprotein cholesterol $\left(\mathrm{HDL}_{\mathrm{c}}\right)$, triglyceride, and glucose concentrations in accordance with the laboratory techniques and protocols used by the Lipid Research Clinic Program Study. ${ }^{19}$ The concentration of LDL was calculated using the Friedewald equation, ${ }^{20}$ which is a valid estimate of $\mathrm{LDL}_{c}$ when triglyceride concentrations are below $350 \mathrm{mg} / \mathrm{dl}$. Samples from 24 subjects were excluded from the $\mathrm{LDL}_{\mathrm{c}}$ analyses because triglyceride concentrations exceeded 350 $\mathrm{mg} / \mathrm{dl}$. A questionnaire was administered on work history, health behaviour, and use of medication. Subjects who reported health conditions or current use of medications known to influence risk factors for ischaemic heart disease were excluded from the analyses. For the blood pressure analyses, we excluded 18 subjects who reported the use of antihypertensive drugs; for fasting glucose, we excluded two subjects taking hypoglycaemic drugs, and for lipoproteins, we excluded five subjects taking corticosteroids and lipid lowering or thyroid medications. Because antihypertensive medications could influence the lipid concentrations, we also conducted the lipid analyses without subjects taking these. As the results were unaltered, they are not reported here.

\section{ANALYSES}

We examined the relation of exposure to $\mathrm{CS}_{2}$ with total serum cholesterol, low and high density lipoprotein cholesterol, triglyceride, and fasting glucose concentrations, and systolic and diastolic blood pressure. General linear models were used in all univariate and multivariate linear regression analyses to examine differences in each risk factor by exposure level (none, low, moderate, and high). To test for trend, we also examined exposure to $\mathrm{CS}_{2}$ as a continuous variable. In this analysis, we assigned each worker the mean $\mathrm{CS}_{2}$ exposure (ppm) associated with his current job title category as depicted in table 1. Non-exposed workers were assigned a zero exposure value. Because of possible differences in other chemical exposures between the exposed and unexposed groups, all analyses were repeated without the unexposed group to examine the consistency of the data.

Because of the data which suggested that the effect of $\mathrm{CS}_{2}$ on ischaemic heart disease is reversible, we were primarily interested in examining the effect of current $\mathrm{CS}_{2}$ exposure on the risk factors for ischaemic heart disease. We did, however, also examine cumulative exposure. Because historical personal exposures were difficult to reconstruct and because our records indicated that $81.8 \%$ of the exposed employees worked in their current job assignment for the duration of their employment with the company, we examined a cumulative exposure effect by entering duration of employment 
into the final multivariate model containing the current exposure categories. The distributions of serum triglyceride and blood lead concentrations were normalised by a natural $\log$ transformation.

We considered the following variables as potential confounders in the analyses of serum lipids: age, body mass index $\left(\mathrm{kg} / \mathrm{m}^{2}\right)$, education (less than 12 years $v 12$ or more years), current smoking (yes $v$ no), current alcohol consumption (none, less than one drink a week, one or more drinks a week), and race (white $v$ non-white). In the blood pressure analyses, we examined the above variables as well as blood lead and haemoglobin concentrations and pulse rate.

\section{Results}

The $\mathrm{CS}_{2}$ exposed workers were significantly older, worked more years at the plant, had higher blood lead concentrations, and were less likely to drink alcoholic beverages than the comparison group of unexposed workers (table 2). Also, a greater percentage of nonwhite subjects was seen in the highest exposure group and the $\mathrm{CS}_{2}$ exposed workers were slightly less educated than the unexposed comparison group, but these differences were not statistically significant. No differences by exposure were found for body mass index or smoking.

In multivariate analyses, in which current exposure was examined as a continuous variable, we found a significant positive linear trend in $\mathrm{LDL}_{\mathrm{c}}$ (regression coefficient $=0.04 \mathrm{mmol} / \mathrm{l}, \mathrm{p}=0.02$ ) and a non-significant positive linear trend in total cholesterol (regression coefficient $=0.03 \mathrm{mmol} / \mathrm{l}, \mathrm{p}=0.09$ ) with increasing job exposure level, after adjustment for age, body mass index, and smoking. For both $\mathrm{LDL}_{\mathrm{c}}$ and total cholesterol concentration, further adjustment for alcohol consumption, educational level, race, and duration of employment, did not add to the predictive value of the multivariate model and did not modify the effect of exposure. When we limited the analyses to the $\mathrm{CS}_{2}$ exposed workers, the positive linear trend became slightly stronger for both $\mathrm{LDL}_{\mathrm{c}}$ (regression coefficient $=0.05 \mathrm{mmol} / 1, \mathrm{p}$ $=0.03$ ), and total cholesterol concentration (regression coefficient $=0.05 \mathrm{mmol} / \mathrm{l}, \mathrm{p}=0.07$ ).

The adjusted means and standard error (SE) terms for $\mathrm{LDL}_{\mathrm{c}}$ and total cholesterol concentrations based on the analyses of exposure as a categorical variable (table 3) were comparable with the predicted means based on the analysis of exposure as a continuous variable. The moderate exposure group had a mean $\mathrm{LDL}_{\mathrm{c}}$ concentration that was $0 \cdot 10 \mathrm{mmol} / \mathrm{l}$ greater than the non-exposed group $(3.19 v 3.09 \mathrm{mmol} / 1, \mathrm{p}=$ 0.43 ), and the high exposure group had a mean $\mathrm{LDL}_{c}$ concentration that was $0.32 \mathrm{mmol} / 1$ greater than the non-exposed group ( $3.41 v 3.09 \mathrm{mmol} / \mathrm{l}, \mathrm{p}=0.02)$. Similarly, for total cholesterol concentration, the moderate exposure group had a value that was 0.07 $\mathrm{mmol} / \mathrm{l}$ greater than in the non-exposed group $(5.19 v$ $5.12 \mathrm{mmol} / \mathrm{l}, \mathrm{p}=0.54)$ and the high exposure group had a mean total cholesterol concentration that was $0.26 \mathrm{mmol} / 1$ greater than the non-exposed group $(5.38 v 5.12 \mathrm{mmol} / \mathrm{l}, \mathrm{p}=0.08)$. Categorical analysis limited to $\mathrm{CS}_{2}$ exposed workers showed a slightly stronger exposure effect for both $\mathrm{LDL}_{\mathrm{c}}$ and total cholesterol concentration.

We also found a significant positive linear trend in diastolic blood pressure with increasing exposure to $\mathrm{CS}_{2}$ (regression coefficient $=0.42, \mathrm{p}=0.04$ ) after adjustment for age, body mass index, and the log of blood lead concentration. This trend became stronger in the analysis limited to the $\mathrm{CS}_{2}$ exposed workers (regression coefficient $=0.87, \mathrm{p}<0.01$ ). Table 3 depicts the adjusted means and SE terms for diastolic blood pressure for each $\mathrm{CS}_{2}$ exposure category. The high exposure group had a mean diastolic blood pressure that was $3.15 \mathrm{~mm} \mathrm{Hg}$ greater than the nonexposed group (76.55 v73.39 $\mathrm{mm} \mathrm{Hg}, \mathrm{p}=0.09$ ); when we limited the analysis to the $\mathrm{CS}_{2}$ exposed workers, the high exposure group had a mean diastolic blood pressure that was $5.00 \mathrm{~mm} \mathrm{Hg}$ greater

Table 2 Distribution of selected characteristics by $C S_{2}$ exposure state among 410 male textile workers

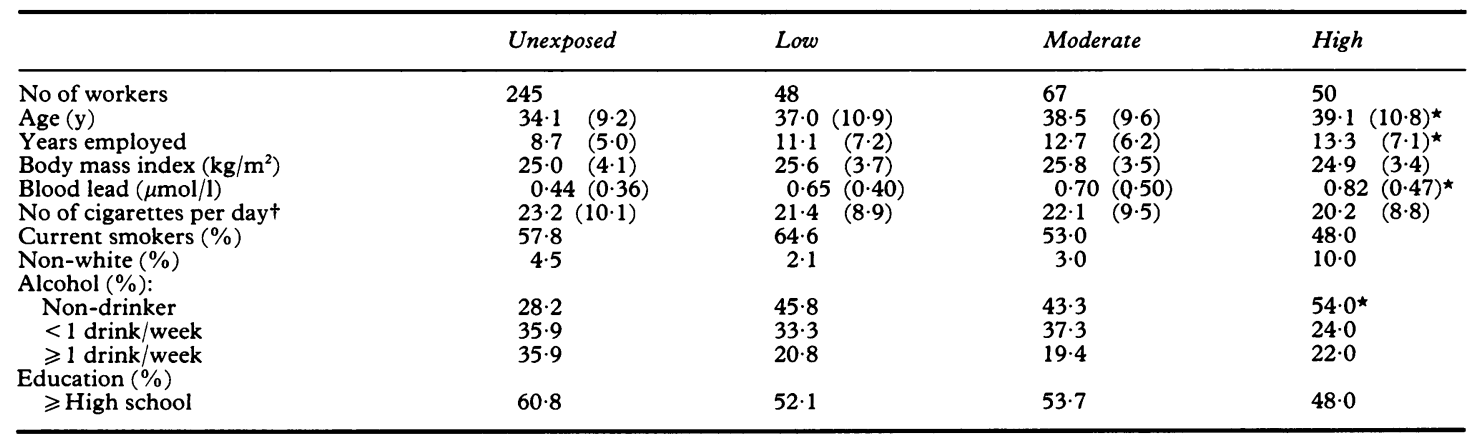

For continuous variables, data are presented as mean (SD).

${ }^{\star} p \leqslant 0.05$, significant difference in means or proportion by exposure level.

†For smokers only. 
Table 3 Adjusted means (SEs) for selected coronary heart disease risk factors by $\mathrm{CS}_{2}$ exposure group

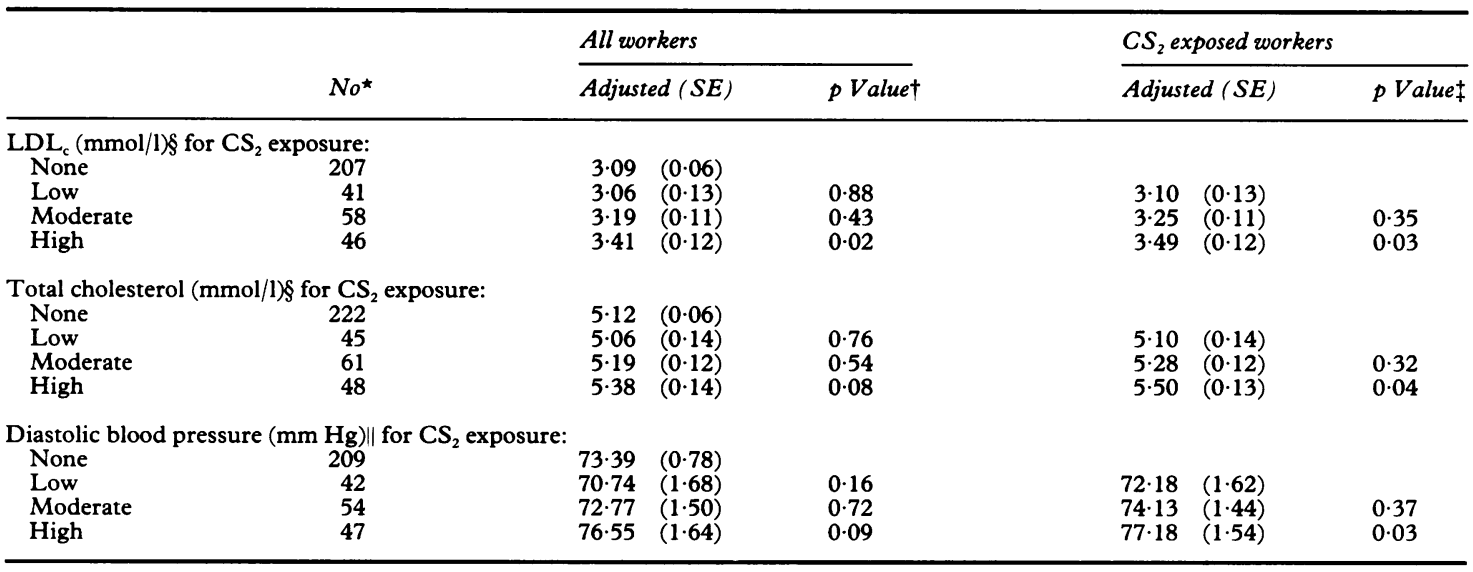

*Number of subjects in analyses after exclusions due to missing covariate data.

tExposed $v$ non-exposed group.

†Exposed $v$ low exposed group.

\$Adjusted for age, body mass index, and smoking.

Adjusted for age, body mass index, and log of blood lead concentration.

than the low exposure group $(77 \cdot 18 v 72 \cdot 18 \mathrm{~mm} \mathrm{Hg}$, $\mathrm{p}=0.03)$. Further adjustment for haemoglobin, alcohol consumption, educational level, smoking, race, and duration of employment did not add to the predictive value of the model or modify the magnitude of the effect of $\mathrm{CS}_{2}$ on diastolic blood pressure.

Exposure to $\mathrm{CS}_{2}$ was not related to systolic blood pressure after adjustment for body mass index, pulse rate, and the log of blood lead concentration $\left(\mathrm{CS}_{2}\right.$ regression coefficient $=0.13, p=0.57)$. Furthermore, the results were not altered when the analysis was limited to the exposed workers, or when blood lead concentration was removed from the model. The inclusion of pulse rate in the final model did not result in an overadjustment for an effect of $\mathrm{CS}_{2}$, as $\mathrm{CS}_{2}$ was not related to pulse rate.

Blood lead concentration was an important predictor of systolic and diastolic blood pressure. After we adjusted for age, body mass index, pulse rate, and $\mathrm{CS}_{2}$ exposure, the log of blood lead concentration was positively related to systolic blood pressure (regression coefficient $=1.82, p=0.04)$; this effect was strengthened when the analyses were limited to the $\mathrm{CS}_{2}$ exposed workers (regression coefficient $=3 \cdot 06$, $\mathrm{p}=0.04$ ). The log of blood lead concentration, however, was positively related to diastolic blood pressure only in the analysis limited to the $\mathrm{CS}_{2}$ exposed workers (regression coefficient $=2 \cdot 38, \mathrm{p}=$ 0.06 ) after adjustment for exposure to $\mathrm{CS}_{2}$, age, and body mass index.

By univariate and multivariate analyses, we did not find any association between $\mathrm{CS}_{2}$ exposure and $\mathrm{HDL}_{\mathrm{c}}$ triglyceride, or fasting glucose concentrations.

\section{Discussion}

The results indicate that modest exposure to $\mathrm{CS}_{2}$ may raise $\mathrm{LDL}_{\mathrm{c}}$ concentration. Because $\mathrm{LDL}_{\mathrm{c}}$ is the largest component of total cholesterol, and because $\mathrm{CS}_{2}$ had no obvious effect on $\mathrm{HDL}_{\mathrm{c}}$ concentration, the effect of $\mathrm{CS}_{2}$ on total cholesterol concentration found in this study appears to be attributed to the effect of $\mathrm{CS}_{2}$ on $\mathrm{LDL}_{c}$ concentration. An effect of $\mathrm{CS}_{2}$ on $\mathrm{LDL}_{\mathrm{c}}$ concentration is consistent with the type of heart disease (atherosclerotic) found in occupationally exposed populations, ${ }^{1-5}$ and with the increase in $\beta$-lipoprotein concentrations found in laboratory rabbits exposed to $\mathrm{CS}_{2}{ }^{21}$ Also, because reductions in $\mathrm{LDL}_{\mathrm{c}}$ and total cholesterol concentrations reverse or slow the progression of atherosclerotic lesions, ${ }^{20-26}$ and reduce the risk of coronary events, ${ }^{27}$ a $\mathrm{CS}_{2}$ effect on $\mathrm{LDL}_{\mathrm{c}}$ concentration is consistent with the apparent reversible effect that $\mathrm{CS}_{2}$ has on risk of ischaemic heart disease.

We are not aware of any other study which examined $\mathrm{LDL}_{\mathrm{c}}$ among populations exposed to $\mathrm{CS}_{2}$. Other studies have reported increases in total cholesterol concentration among workers exposed to $\mathrm{CS}_{2}$ concentrations that were much higher than those experienced by the current study population. Raised total cholesterol concentrations were found among Japanese viscose rayon workers exposed to $\mathrm{CS}_{2}$ concentrations ranging from 15 to $65 \mathrm{ppm}$, but not among workers exposed to lower concentrations, ranging from 5 to $19 \mathrm{ppm}^{8}$ Similarly, increases in total cholesterol concentration were found among Japanese workers exposed to $\mathrm{CS}_{2}$ concentrations ranging from 40 to $50 \mathrm{ppm}$ in two plants in the early 
1950 s, but not among workers in the same two plants in 1965 when exposures ranged from 5 to $15 \mathrm{ppm} .^{10}$ Among viscose rayon workers in Finland, exposure was not related to total cholesterol concentration, ${ }^{9}$ but only $61.5 \%$ of the exposed study participants were currently exposed at the time of the study and current exposures were below $20 \mathrm{ppm}$. In the present study, we found a non-significant positive linear trend in total cholesterol concentration with increasing $\mathrm{CS}_{2}$ exposure. Average exposure concentrations by job title ranged from $0.6 \mathrm{ppm}$ to $11.8 \mathrm{ppm}$.

The mean $\mathrm{LDL}_{\mathrm{c}}$ concentration in the high exposure group is in the borderline high risk range $(\geqslant 3.36 \mathrm{mmol} / \mathrm{l})$ established by the National Heart, Lung, and Blood Institute. ${ }^{28}$ The Lipid Research Clinics (LRC) prevalence follow up study reported that a $0.78 \mathrm{mmol} / 1(30 \mathrm{mg} / \mathrm{dl})$ difference in $\mathrm{LDL}_{\mathrm{c}}$ concentration was associated with a $65 \%$ increase in mortality from coronary heart disease among men during an eight year period. ${ }^{29}$ In the LRC population, the differences in $\mathrm{LDL}_{\mathrm{c}}$ concentration by exposure category would translate to an increased coronary heart disease risk of $26 \%$ and $9 \%$ for the high and moderate exposure groups respectively. A mortality study of four rayon textile plants in the United States, that included our study plant, found a $24 \%$ increase in mortality from ischaemic heart disease among workers that had similar job assignments as our high exposure group. ${ }^{30}$ The mortality study did not report $\mathrm{CS}_{2}$ exposure levels at these four plants, however.

As well as an effect on $\mathrm{LDL}_{\mathrm{c}}$ concentration the results indicate that exposure to $\mathrm{CS}_{2}$ may also have an effect on diastolic blood pressure. As with $\mathrm{LDL}_{\mathrm{c}}$ and total cholesterol concentrations, the trend in diastolic blood pressure found among all workers was strengthened in the analysis limited to the $\mathrm{CS}_{2}$ exposed workers. It is possible that potential differences in other chemical exposures between the $\mathrm{CS}_{2}$ exposed and unexposed groups may influence the magnitude of the association found between exposure state and blood pressure and lipoproteins. For example, the group not exposed to $\mathrm{CS}_{2}$ had potential exposure to caprolactam, which has been reported to raise blood pressure in animal studies. ${ }^{31}$ Because the exposed population is more homogeneous with regard to chemical exposures than the total $\mathrm{CS}_{2}$ exposed and non-exposed group, the analyses excluding the nonexposed group could provide a more sensitive indication of a possible effect of exposure to $\mathrm{CS}_{2}$.

Our results do not indicate an effect of exposure to $\mathrm{CS}_{2}$ on systolic blood pressure. Reports from a study population in Finland, however, showed raised diastolic and systolic blood pressure among $\mathrm{CS}_{2}$ exposed workers. ${ }^{12}$ Reasons for this discrepancy are not obvious, as current exposures (less than $20 \mathrm{ppm}$ ) and the average duration of employment of the Finnish workers were comparable with that of our study population. The Finnish study, however, did not consider the potential for confounding exposure to inorganic lead, which was positively correlated to $\mathrm{CS}_{2}$ exposure and blood pressure in this study.

The relation of blood lead concentration to diastolic and systolic blood pressure is of interest. The blood lead concentrations, which ranged from a mean of $0.44 \mu \mathrm{mol} / 1$ for the unexposed $\mathrm{CS}_{2}$ group to 0.82 $\mu \mathrm{mol} / 1$ for the high exposed $\mathrm{CS}_{2}$ group, are comparable with the range of exposures identified in the general United States population. ${ }^{32}$ The results are consistent with the hypothesis that low to moderate exposure to lead is related to increases in blood pressure as shown in animal studies, ${ }^{334}$ and supported by associations found in several, ${ }^{35-37}$ but not all ${ }^{38}$ epidemiological studies.

One strength of our study is that we were able to examine and control for several potential confounders, such as blood lead concentration, body mass index, race, smoking, and educational level: variables that are often not available in occupational studies. One limitation, however, is that we were not able to control for potential differences in other characteristics, such as diet or physical activity. The fact that there were no differences in the basic pay rate of the viscose rayon workers by exposure category, however, suggests that the workers were a relatively homogeneous group. Another limitation is the potential for selection bias. Workers with health concerns may have been more likely to participate in the study, but this could have been equally true for exposed and non-exposed workers. Because demographic data were not collected on nonparticipants we are unable to consider the issue of selection bias in detail. We did, however, examine the distribution of workers taking antihypertensive medications by degree of exposure. Although we found no statistically significant differences, we did find a slightly greater percentage of antihypertensive use among the low $(6.3 \%)$ and moderate $(9.0 \%)$ exposure groups than among the non-exposed $(3.3 \%)$ and high exposure groups $(2 \cdot 0 \%)$. It is possible that these slight differences could result in an underestimate of an effect of $\mathrm{CS}_{2}$ on blood pressure in the low and moderate exposure groups.

In 1989, OSHA reduced the eight hour TWA permissible exposure limit for $\mathrm{CS}_{2}$ from $20 \mathrm{ppm}$ to 4 $\mathrm{ppm},{ }^{39}$ because of findings suggesting that exposures within the range of $20 \mathrm{ppm}$ are associated with cardiovascular, ${ }^{5630}$ neurological, ${ }^{30}$ and possible reproductive effects. ${ }^{4041}$ The moderate exposure group, which had $\mathrm{CS}_{2}$ exposures in the range of the current OSHA standard, showed no statistically significant differences in $\mathrm{LDL}_{\mathrm{c}}$ concentration and diastolic blood pressure compared with the nonexposed group. The lack of statistically significant increases in these risk factors among the moderate exposure group, however, may be due to the 
relatively large SE terms and the small sample size of the moderate exposure group: our power to detect the $0.10 \mathrm{mmol} / 1$ difference in $\mathrm{LDL}_{\mathrm{c}}$ concentration between the moderate and non-exposed group was only $56 \%$. Also, because we found a significant linear trend in $\mathrm{LDL}_{\mathrm{c}}$ concentration and diastolic blood pressure with increasing exposure to $\mathrm{CS}_{2}$, the results support the NIOSH recommended exposure limit of $1 \mathrm{ppm}$, which was established to provide a margin of safety for the estimated 40000 United States workers exposed to $\mathrm{CS}_{2}{ }^{42}$

The results of this study indicate that relatively modest exposure to $\mathrm{CS}_{2}$ may raise $\mathrm{LDL}_{\mathrm{c}}$ concentration and diastolic blood pressure. This suggests mechanisms by which $\mathrm{CS}_{2}$ exposure may increase the risk of ischaemic heart disease. Our findings also confirm other studies which show that lead exposure increases diastolic and systolic blood pressure.

1 Hernberg S, Partanen T, Nordman C-H, Sumari P. Coronary heart disease among workers exposed to carbon disulphide. $B r$ $J$ Ind Med 1970;27:313-25.

2 Tolonen $M$, Hernberg $S$, Nurminen $M$. A follow up study of coronary heart disease in viscose rayon workers exposed to carbon disulphide. Br J Ind Med 1975;32:1-10.

3 Tolonen $M$, Nurminen $M$, Hernberg S. Ten-year mortality of workers exposed to carbon disulphide. Scand J Work Environ Health 1979;5:109-14.

4 Tiller JR, Schilling RSF, Morris JN. Occupational toxic factor in mortality from coronary heart disease. BMJ 1968;IV: 407-11.

5 Sweetnam PM, Taylor SWC, Elwood PC. Exposure to carbon disulphide and ischaemic heart disease in a viscose rayon factory. $\mathrm{Br} J$ Ind Med 1986;44:220-7.

6 Nurminen $M$, Hernberg $S$. Effects of intervention on the cardiovascular mortality of workers exposed to carbon disulphide: a 15 year follow up. $\mathrm{Br} J$ Ind Med 1985;42:32-5.

7 Oliver LC, Weber RP. Chest pain in rubber chemical workers exposed to carbon disulphide and methaemoglobin formers. Br J Ind Med 1984;41:296-304.

8 Harashima S, Toyama T, Sakurai T. Serum cholesterol level of viscose rayon workers. Keio J Med 1960;9:81-90.

9 Hernberg S, Nordman C-H, Partanen T, Christiansen V, Virkola P. Blood lipids, glucose tolerance and plasma creatinine in workers exposed to carbon disulphide. Work Environment and Health 1971;8:11-7.

10 Toyamoa $T$, Sakurai $H$. Ten-year changes in exposure level and toxicological manifestations in carbon disulphide workers. In: Briefer H, Teisinger J, eds, Toxicology of carbon disulphide. Amsterdam: Excerpta Medica Foundation 1967:197-204.

11 Mangeri S, Cavalleri A, Mangeri U, Taccola A. New aspects in the pathogenic mechanism of carbon disulphide toxic action. Med Lav 1971;62:398-403.

12 Magos $\mathrm{L}$. The clinical and experimental aspects of $\mathrm{CS}_{2}$ exposure on brain catecholamines in rats. $\mathrm{Br} J$ Pharmacol 1970;39: 26-33.

13 Fajen J, Albright B, Leffingwell SS. A cross-sectional medical and industrial hygiene survery of workers exposed to carbon disulfide. Scand JW ork Environ Health 1981;7 (suppl 4):20-7.

14 Putz-Anderson V, Albright BE, Lee ST, Johnson BL, Chrislip DW, Taylor BJ, et al. A behavioral examination of workers exposed to carbon disulfide. Neurotoxicology 1983;4:67-78.

15 Johnson BL, Boyd J, Burg JR, Lee ST, Xintaras C, Albright BE. Effects on the peripheral nervous system of workers' exposure to carbon disulfide. Nedurotoxicology 1983;4:53-66.

16 Eller P. NIOSH manual of analytical methods, 3rd ed. Cincinnati, Ohio: US Depart of Health and Human Services, National Institute for Occupational Safety and Health; 1986. NIOSH publ No 84-10).

17 In-depth industrial hygiene report of the American Enka Company. Cincinnati, OH: April 1982. (NTIS PB83221689.)

18 American Conference of Governmental Industrial Hygienists. Guide to occupational exposure values, Cincinnati, Ohio: 1986.

19 Manual of Laboratory Operations. Lipid Research Clinic Program. Lipid and Lipoprotein Analyses. Bethesda, MD: US Dept of Health, Education, and Welfare, National Institutes of Health publication (NIH) 75-628, 1975.
20 Friedewald WT, Levy RI, Frederickson DS. Estimation of the concentration of LDL-c in plasma without the use of the preparative ultracentrifuge. Clin Chem 1972;18:499-502.

21 Cohen AE, Scheel LD, Kopp JF, et al. Biochemical mechanisms in chronic carbon disulfide poisoning. Am Ind Hyg Assoc J 1959;20:303-23.

22 Brensike JF, Levy RI, Kelsey SF, et al. Effects of therapy with cholestyramine on progression of coronary arteriosclerosis: results of the NHLBI Type II Coronary Intervention Study. Circulation 1984;69:313-24.

23 Kane JP, Malloy MJ, Ports TA, Phillips NR, Diehl JC, Havel $\mathrm{RJ}$. Regression of coronary atherosclerosis during treatment of familial hypercholesterolemia with combined drug regimens. JAMA 1990;264:3007-12.

24 Cashin-Hemphill L, Mack WJ, Pogoda J, Sanmarco ME, Azen SP, Blankenhorn DH. Beneficial effects of colestipol-niacin on coronary atherosclerosis: a 4-year follow-up. JAMA 1990; 264:3013-7.

25 Brown G, Albers JJ, Fisher LD, et al. Regression of coronary artery disease as a result of intensive lipid-lowering therapy in men with high levels of apolipoprotein B. $N$ Engl J Med 1990;323:1289-98.

26 Blankenhorn DH, Nessim SA, Johnson RL, et al. Beneficial effects of combined colestipol-niacin therapy on coronary atherosclerosis and coronary venous bypass grafts. JAMA 1987;255:3233-40.

27 Tyroler HA. Lowering plasma cholesterol levels decreases risk of coronary heart disease: an overview of clinical trials. In: Steinberg D, Olefsky JM, eds. Hypercholesterolemia and atherosclerosis. New York, NY: Churchill Livingstone Inc 1987:99-116.

28 The Expert Panel. Report of the National Cholesterol Education Program Expert Panel on detection, evaluation, and treatment of high blood cholesterol in adults. Arch Intern Med 1988;148:36-69.

29 Jacobs DR, Membane IL, Bangdiwala SI, Criqui MH, Tyroler HA. For the Lipid Research Clinics program. High density lipoprotein cholesterol as a predictor of cardiovascular disease mortality in men and women: The Follow-up study of the Lipid Research Clinics Prevalence Study.Am J Epidemiol 1990;131:32-47.

30 MacMahon B, Monson RR. Mortality in the US rayon industry. J Occup Med 1988;30:698-705.

31 Gross P. Biologic activity of Epsilon-caprolactam. CRC Critical Reviews in Toxicology 1984;13:205-16.

32 Schwartz J. The relationship between blood lead and blood pressure in the NHANES II Survey. Environ Health Perspect 1988;78:15-22.

33 Carmignani M, Boscolo P, Ripanti G, Finelli VN. Effects of chronic exposure to cadmium and/or lead on some neurohumoral mechanisms regulating cardiovascular function in the rat. International conference on heavy metals in the environment. Heidelberg, Germany. 1983;1:557-60.

34 Koop SJ, Perry HM, Glonek T, et al. Cardiac physiologicmetabolic changes after chronic low-level heavy metal feeding. Am J Physiol 1980:239-H22-H30.

35 Weiss ST, Munoz A, Stein A, Sparrow D, Speizer FE. The relationship of blood lead to blood pressure in a longitudinal study of working men. Am J Epidemiol 1986;123:800-8.

36 Rabinowitz M, Bellinger D, Leviton A, Needleman H, Schoenbaum SX. Pregnancy hypertension, blood pressure during labor, and blood lead levels. Hypertension 1984;10:447-51.

37 Harlan WR. The relationship of blood lead levels to blood pressure in the US population. Environ Health Perspect 1988;78:9-13.

38 Pocock SJ, Shaper AG, Ashby D, Delves I, Whitehead IP. Blood Lead concentration, blood pressure, and renal function. $B M J$ 1984;289:872-4.

39 US Department of Labor, Occupational Safety and Health Administration. Air contaminants; final rule. Federal Register 1989;54:2535.

40 Cai SX, Bao YS. Placental transfer, secretion into mother milk of carbon disulphide and the effects on maternal function of female viscose rayon workers. Ind Health 1981;19:15-29.

41 Hemminki K, Niemi ML. Community study of spontaneous abortions: Relation to occupation and air pollution by sulfur dioxide, hydrogen sulfide, and carbon disulfide. Int Arch Occup Environ Health. 1982;51:55-63.

42 Criteria for a recommended standard: Occupational exposure to carbon disulfide. Cincinnati, OH: US Department of Health Education, and Welfare, National Institute for Occupational Safety and Health, publication (NIOSH) 77-156.

Accepted 12 August 199 